\title{
DRYING CHARACTERISTICS OF RHUBARB CUBES AT LOW TEMPERATURE
}

\author{
Tatjana Rubina ${ }^{1}$, Aivars Aboltins ${ }^{1}$, Janis Palabinskis ${ }^{1}$ \\ ${ }^{1}$ Latvia University of Life Sciences and Technologies, Latvia \\ tatjana.rubina@1lu.lv, aivars.aboltins@1lu.lv, janis.palabinskis@1lu.lv
}

\begin{abstract}
Rhubarbs are not only a delicious product widely used in the bakery and confectionary. Rhubarb's roots and stems are also used for medical purposes. Since this agricultural product has a seasonal nature, it is important to preserve it for later months. Drying is one of the effective preservation methods to keep rhubarbs in good quality for longer time. The aim of this study is to investigate dynamics of drying parameters of rhubarb cubes, including 3D shrinkage changes, applying infrared drying method at low drying temperature. Within this study several sets of experiments were performed for rhubarb cubes with four different thicknesses: $5 \mathrm{~mm}, 10$ $\mathrm{mm}, 15 \mathrm{~mm}$ and $20 \mathrm{~mm}$. Within the framework of the study, the pieces of unpeeled and peeled rhubarb stems were dried in an infrared dryer at a temperature of 41 degrees with ventilation. During the experiments the samples were regularly weighed and shrinkage parameters in three dimensions were recorded. Obtained experiment results indicate that the water removal difference between peeled and unpeeled rhubarb cubes reaches up to $16 \%$ at the beginning of experiments in case of thicker samples and during the first 4 hours of drying in case of thinner samples, but it disappears to the end of the experiment. The analysis results of shrinkage parameters showed that the height and width of rhubarbs samples change much more than thickness. While nonlinear multivariable regression analysis highlighted that there exists a strong relationship between the moisture concentration, drying time and surface area ratio.
\end{abstract}

Keywords: diffusion, IR, mathematical modelling, rhubarb drying, shrinkage.

\section{Introduction}

Rhubarb is a sour-tasting vegetable belonging to the family of Polygonaceae [1]. It is a long-lived perennial plant with edible stalks [2] that can be consumed fresh with or without sugar, as a juice, or in processed form, for example, candies, compote, pie, cake, sauce, jam, wine. Rhubarb is an extremely healthy product and a rich source of antioxidants and dietary fibers. It consists of up to $93 \%$ water and is among the highest moisture of all common vegetable crops [3]. Rhubarb contains a number of naturally occurring acids, minerals (potassium $-288 \mathrm{mg}$, calcium $-86 \mathrm{mg}$, phosphorus $-14 \mathrm{mg}$, magnesium $12 \mathrm{mg}$ per $100 \mathrm{~g}$ etc.) and vitamins (vitamin $\mathrm{C}-8 \mathrm{mg}, \mathrm{K}-29.3 \mu \mathrm{g}$, folate $-7 \mu \mathrm{g}, \mathrm{A}-$ $5 \mu \mathrm{g}$ etc.), is extremely low in fat with few calories, cholesterol and caffeine free [4]. Nutritionists often recommend it for people who are struggling to lose weight and remain healthy. Rhubarb's roots and stems are used for medical purposes [5;6]. Rhubarb possesses neuroprotective, anti-inflammatory, antibacterial [7], antimicrobial [8], antiviral [9], antioxidative [10], purgative and anticancer properties [11].

There exist various types of rhubarb preservation methods that allow increasing "storage life" of the rhubarb by removing moisture from it and preventing growth of microorganisms: canning, pickling, making sauce, jam or jelly, drying, freezing, and fermenting into wine. In this research the rhubarb infrared drying will be under consideration because of its gaining popularity in food processing and provided advantages. Dehydrated or dried rhubarb can be used for a wide range of applications, especially bakery and confectionary, for example, rhubarb cake, muffins, crisp, crumble, in sweets. It can be also used with savoury flavours to complement the taste of meat such as lamb, pork and black pudding.

Many studies have been devoted to drying: hot air drying, IR drying, microwave, convective, freeze, vacuum, sun. Foodstuffs with high moisture content can be effectively dried using combination methods [12], for example hybrid drying, like hot air-freeze drying [13] and infrared-freeze drying [14]. As argue Antal [12] hot air drying is the most commonly employed commercial technique for drying vegetables and fruits, but its major disadvantages are the long drying time even at temperatures near $60^{\circ} \mathrm{C}$, resulting in the degradation of the material quality. By contrast, infrared drying (IR) has many advantages including uniform heating, high heat transfer rate, reduced processing time and energy uptake and improved product quality [12;15]. IR is an effective method of dehydration especially in drying of heat sensitive materials [16]. Nowak and Lewinski [17] listed such advantages of IR drying as the short time of drying and easy control of material temperature. Drying 
of the products preferring infrared radiation can save the contents of vitamins and other biologically active substances in the dry product at a level of $80-90 \%$ from the baseline [18;19].

The aim of this study is to investigate dynamics of drying parameters of rhubarbs cubes including $3 \mathrm{D}$ shrinkage changes applying IR drying method at low drying temperature.

\section{Materials and methods}

\section{Research object}

The research object of current study is rhubarbs stems (Rheum Rhabarbarum) produced in Latvia. The leaves were cut off, then stems were washed with cold water and blotted. For the investigation purposes, two sets of samples were prepared: peeled (Fig.1.) and unpeeled rhubarb cubes. The stems were cut manually into pieces with 4 different thicknesses $(0.5 \mathrm{~cm}, 1 \mathrm{~cm}, 1.5 \mathrm{~cm}$ and $2 \mathrm{~cm})$ using a sharp knife to have uniform pieces. The rhubarbs cubes were placed on round mesh trays (diameter 20 $\mathrm{cm}$ ) in a single layer. Each sample contains at least 10 pieces on each individual tray.

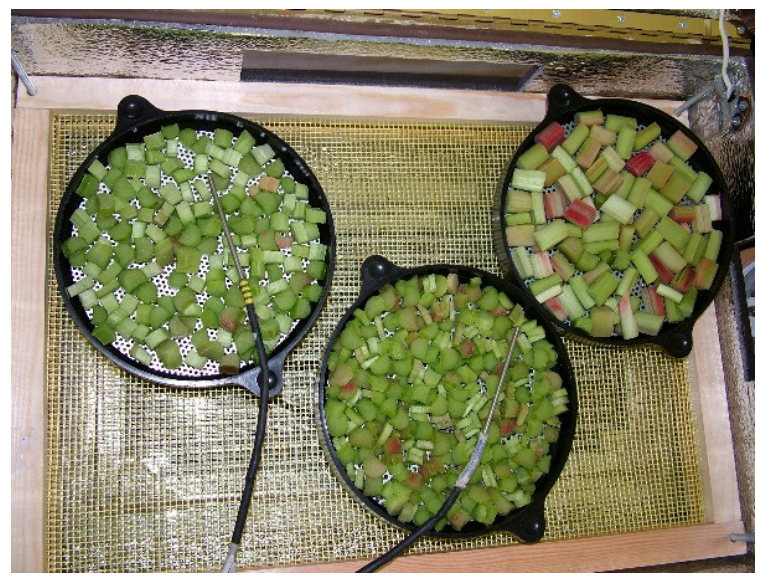

Fig. 1. Peeled rhubarb cubes before drying

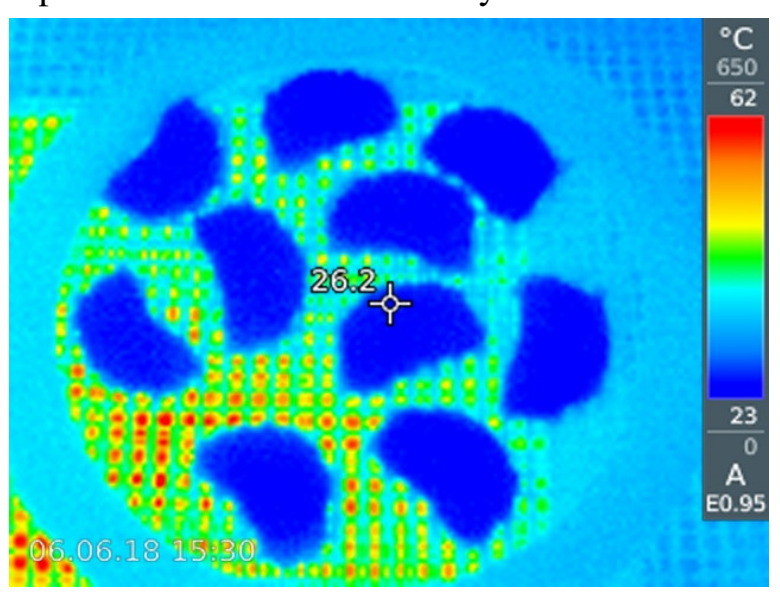

Fig. 2. Rhubarb cubes drying process

\section{Equipment}

The experiments were made at the Grain Drying and Storage Scientific Laboratory at the Latvia University of Life Sciences and Technologies. The infrared (IR) drying chamber $(80 \times 50 \times 30 \mathrm{~cm})$ with the total area $0.8 \mathrm{~m}^{2}$ and a heat source IR (max heating $45-50{ }^{\circ} \mathrm{C}$ ) mounted on the top and bottom of the chamber film was used [18]. The accuracy of the chamber temperature control $\pm 0.3^{\circ} \mathrm{C}$. The applied film power was $140 \mathrm{~W} \cdot \mathrm{m}^{-2}$.

Before and during the drying experiment (Fig. 2) the sample trays each separately were weighed on the digital laboratory balance KERN-440-35N with the maximum load weight $400 \mathrm{~g}$ and precision $\pm 0.01 \mathrm{~g}$. The shrinkage parameters, such as length, width and height (Fig. 3) were measured using a dial caliper.

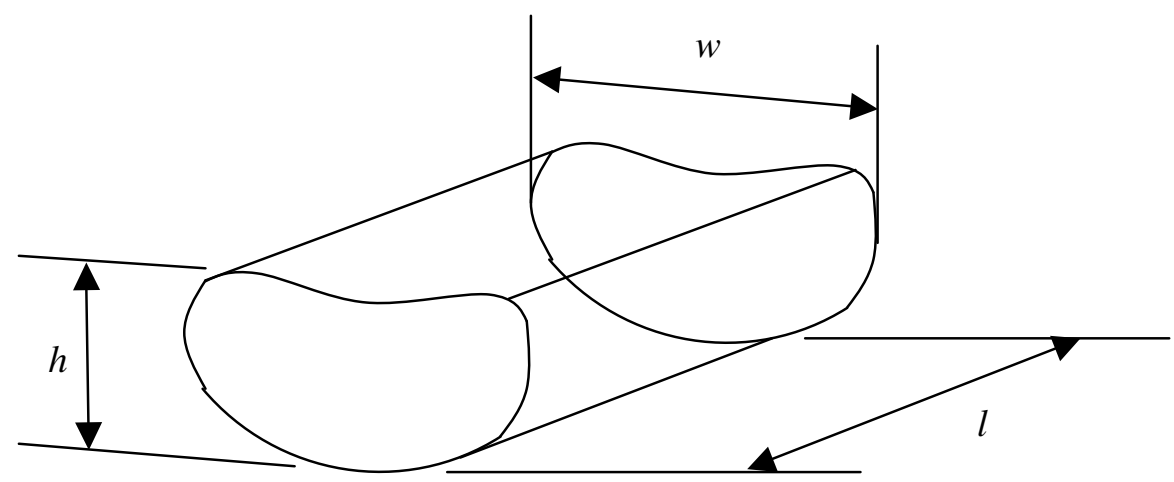

Fig. 3. Rhubarb shrinkage parameters: $w$-width, $h$ - height, $l$ - length or thickness 


\section{Drying procedure}

The weight of each empty tray and the tray with a sample were weighed before the drying experiment.

The samples were placed in the drying chamber tray and dried at a constant temperature $41 \pm 0.3{ }^{\circ} \mathrm{C}$. The experiments were performed with the fan with a total maximum capacity of $100 \mathrm{~m}^{3} \cdot \mathrm{h}^{-1}$ and power $15 \mathrm{~W}$. Drying temperature was chosen based on previously performed studies, which concluded that the drying temperature $40-60{ }^{\circ} \mathrm{C}$ is optimal to preserve vitamins, biologically active substances, natural colour and aroma of the dried products [18].

During drying the experiment samples were regularly weighed to determine the mass changes and the shrinkage parameters, such as length, width and height were measured to determine the shrinkage changes.

The total time of the drying experiment was adapted to the need for determination of dry matter.

\section{Mathematical modelling}

The experimental data sets from the different drying experiments were expressed as moisture concentration $C$ versus the drying time $t$. The moisture concentration in $\%$ at a certain moment in time $t_{i}$ was calculated using the formula (1):

$$
C(\%)=\frac{M_{i}-M_{\infty}}{M_{0}-M_{\infty}} \cdot 100 \%,
$$

where $M_{i}-$ weight of the sample at time moment $t_{i}, \mathrm{~g}$;

$M_{\infty}$ - equilibrium weight of the sample, $\mathrm{g}$;

$M_{0}$ - weight of the sample before drying, g.

The drying coefficient value $K\left(t_{i}\right)$ at certain moment in time $t_{i}$ was calculated using the formula (2) described by Aboltins \& Upitis [20]:

$$
K\left(t_{i}\right)=-\frac{\ln \left(\frac{M_{i}-M_{\infty}}{M_{0}-M_{\infty}}\right)}{t_{i}},
$$

where $t_{i}$-drying time, $\mathrm{h}$.

The diffusion coefficient value $D\left(t_{i}\right)$ at certain moment in time $t_{i}$ was calculated using simplified formula (3) which can be expressed from the relationship between the drying coefficient and moisture diffusion described by Hassini et al. [21]:

$$
D\left(t_{i}\right)=\frac{K\left(t_{i}\right) L^{2}}{\pi^{2}}
$$

where $L$ - length of rhubarbs pieces, mm,

$$
K\left(t_{i}\right) \text { - drying coefficient at certain time moment } t_{i}, h^{-1} \text {. }
$$

The surface area ration $\lambda$ was calculated for drying dynamics determination using formula (4) described by Aboltins et al. [22]:

$$
\lambda=\frac{S_{1}}{S_{2}}=\frac{2 h w}{2 h l+2 w l}=\frac{h w}{l(h+w)}
$$

where $S_{1}$ - sum of the side surface of the sample, $\mathrm{mm}^{2}$;

$S_{2}$-top and bottom area of the sample, $\mathrm{mm}^{2}$;

$h$ - average height of rhubarb pieces, $\mathrm{mm}$;

$w$ - average width of rhubarb pieces, $\mathrm{mm}$;

$l$ - average thickness of rhubarb pieces, $\mathrm{mm}$. 
Spreadsheet software MS EXCEL was used for experimental data processing and analysis. Using the experimental data and performing regression analysis the average thickness of the sample slices and the diffusion coefficient dependence on the moisture concentration were determined.

In order to determine shrinkage dynamics during the drying process, the time series and descriptive statistics from statistical analysis were applied.

In order to perform nonlinear multivariable regression analysis to determine and visualize moisture concentration $C(t, \lambda)$ dependence on the drying time and area ratio, mathematical packages MathCad and Matlab were used.

\section{Results and discussion}

Four series of measurements concerning the drying dynamics of rhubarb cubes were taken: $5 \mathrm{~mm}$, $10 \mathrm{~mm}, 15 \mathrm{~mm}$ and $20 \mathrm{~mm}$ long pieces. The evolution of the moisture concentration during 6 hours of the drying experiment, expressed in (\%), is presented in Fig.4. The analysis result shows that the moisture concentration is changing strongly linearly in both cases and shorter rhubarb cubes lose water faster, as well as the water removal in peeled cubes happens faster. The results of the drying experiments indicate that the noticeable water removal difference between peeled and unpeeled rhubarb cubes with the length up to $10 \mathrm{~mm}$ emerges after 4 drying hours rising to $10 \%$, but disappears to the end of the experiment. In its turn, the water removal difference with the length $15 \mathrm{~mm}$ and longer is detected at the beginning of the experiment and rises to $16 \%$, but disappears during the experiment.

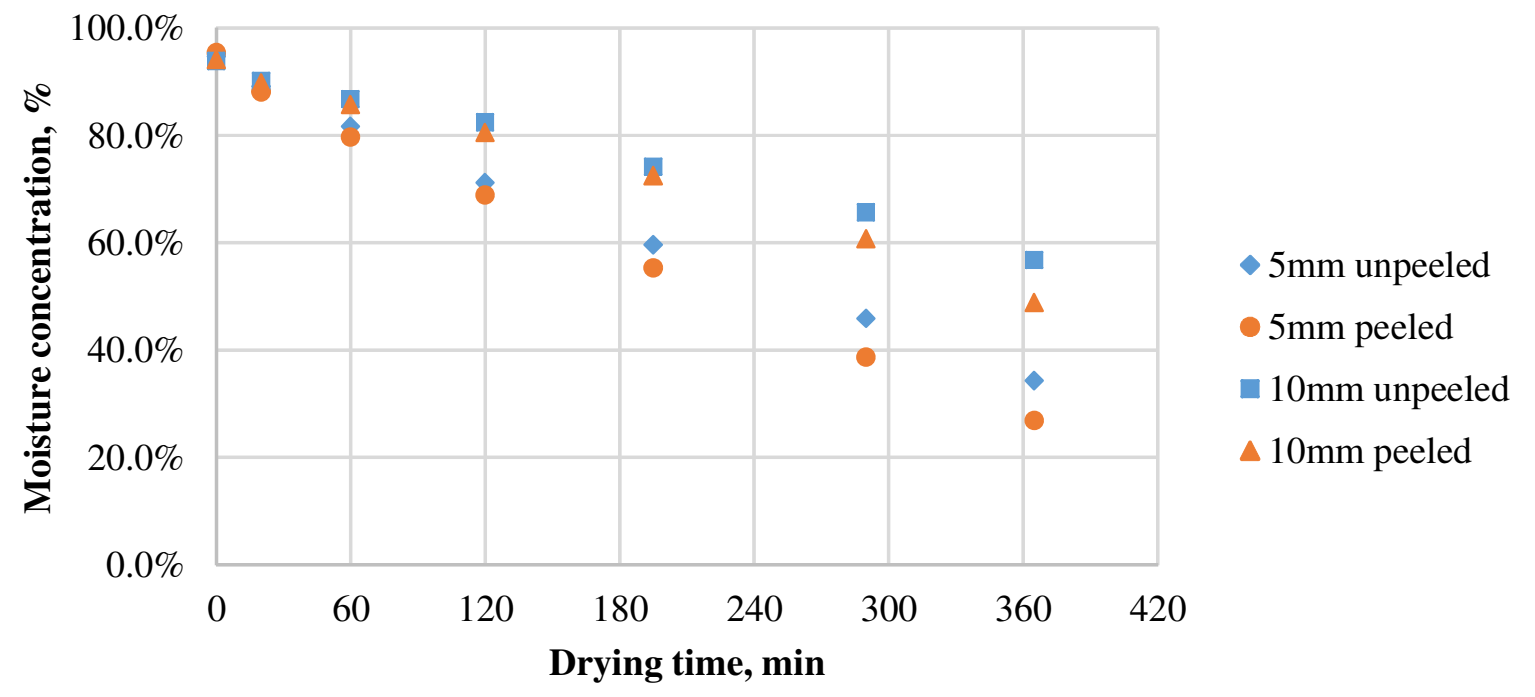

Fig. 4. Moisture concentration dynamics of rhubarb cubes with length $5 \mathbf{~ m m}$ and $10 \mathbf{~ m m}$

The dynamics of drying coefficient, expressed in $\left(h^{-1}\right)$, is presented in Fig. 5. The results show that the character of the drying coefficient changes is similar for rhubarb cubes of different thickness and peeling does not affect the changes' character. The difference between peeled and unpeeled samples remains smaller with increasing the thickness. As it is shown in the figure, the drying coefficient values changes can be described with the second degree polynomial $P_{2}(t)=a_{0}+a_{1} t+a_{2} t^{2}$ during the first 6 hours of the drying process, but considering its behaviour during the drying process until the dry matter is obtained, it can be described with third degree polynomial $P_{3}(t)=a_{0}+a_{1} t+a_{2} t^{2}+a_{3} t^{3}$. Unfortunately, the existing experimental data are not sufficient for assessment of functional dependence and additional experiments are necessary.

In order to estimate the influence of the thickness changes on the diffusion coefficient during the drying process, the functional relationship of the average thickness values versus the moisture concentration was determined (Fig. 6). The analysis results show that the second degree polynomial describes best the relationship.

Fig. 7 shows a comparison of diffusion coefficient values in case of peeled rhubarb cubes with 10 $\mathrm{mm}$ thickness. If the changes of thickness during the drying process are considered, the obtained values of the diffusion coefficient are smaller, but the changes' character remains unchanged. The 
difference is increasing from $20 \%$ to $30 \%$, comparing with the diffusion coefficient values obtained with a constant thickness.

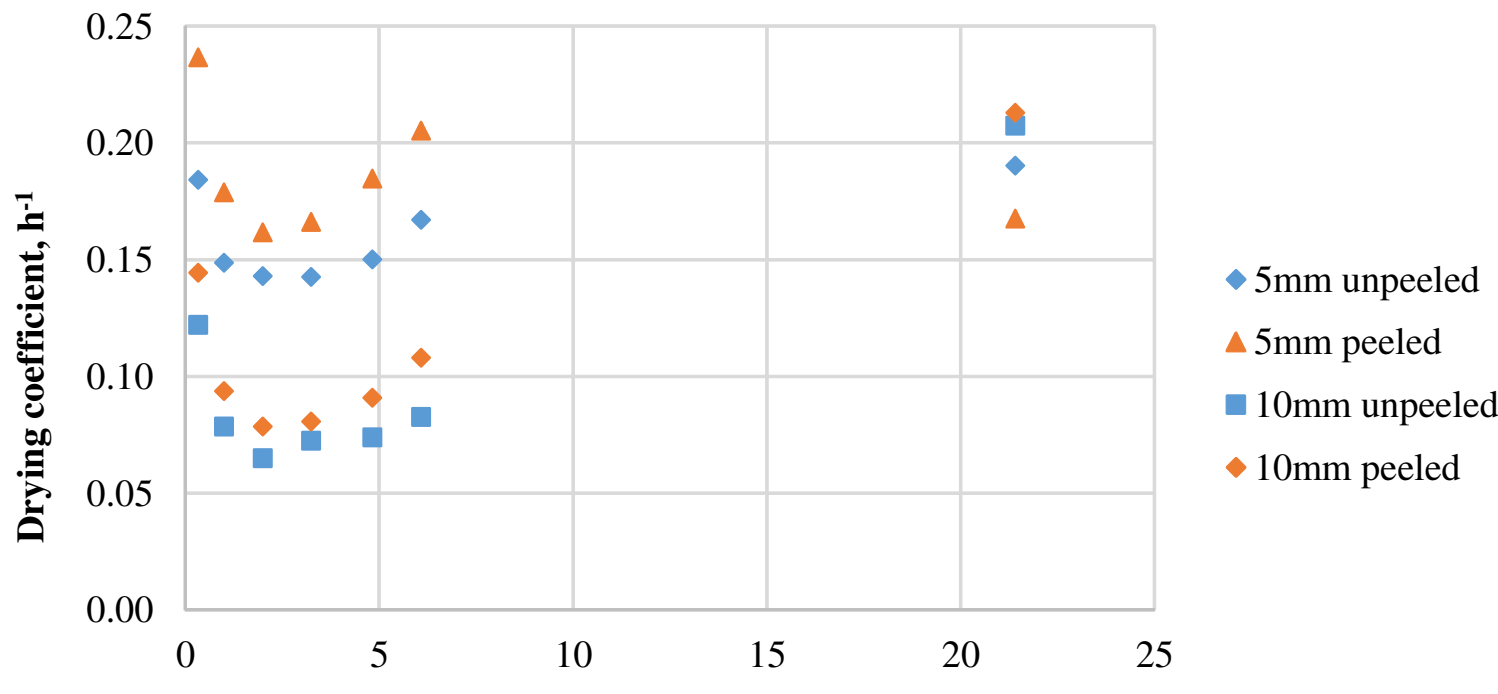

Drying time, $h$

Fig. 5. Drying coefficient dynamics of rhubarb cubes with length $5 \mathbf{~ m m}$ and $10 \mathbf{~ m m}$

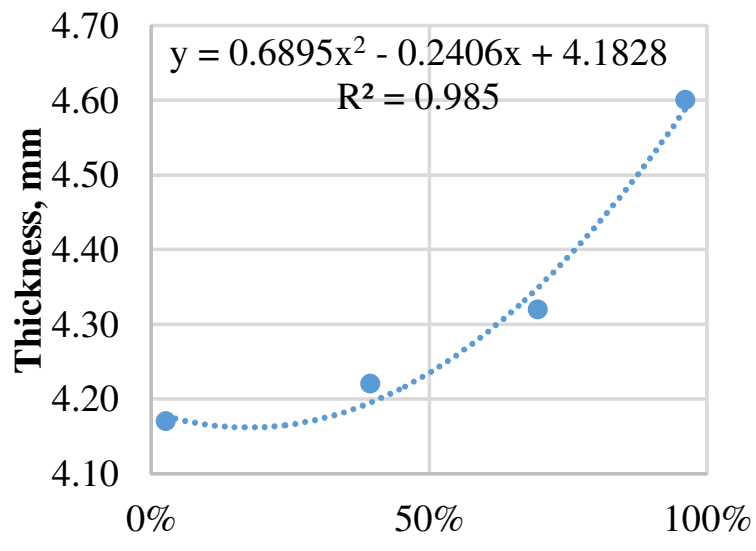

Moisture concentration, $\%$

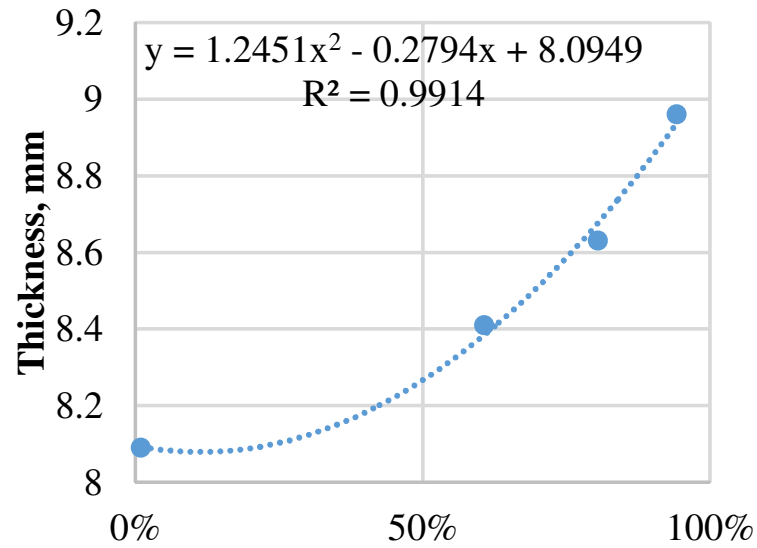

Mositure concentration, $\%$

Fig. 6. Average thickness dependence on moisture concentration:

$\mathrm{a}-5 \mathrm{~mm}$ thick rhubarb cubes; $\mathrm{b}-10 \mathrm{~mm}$ thick rhubarb cubes

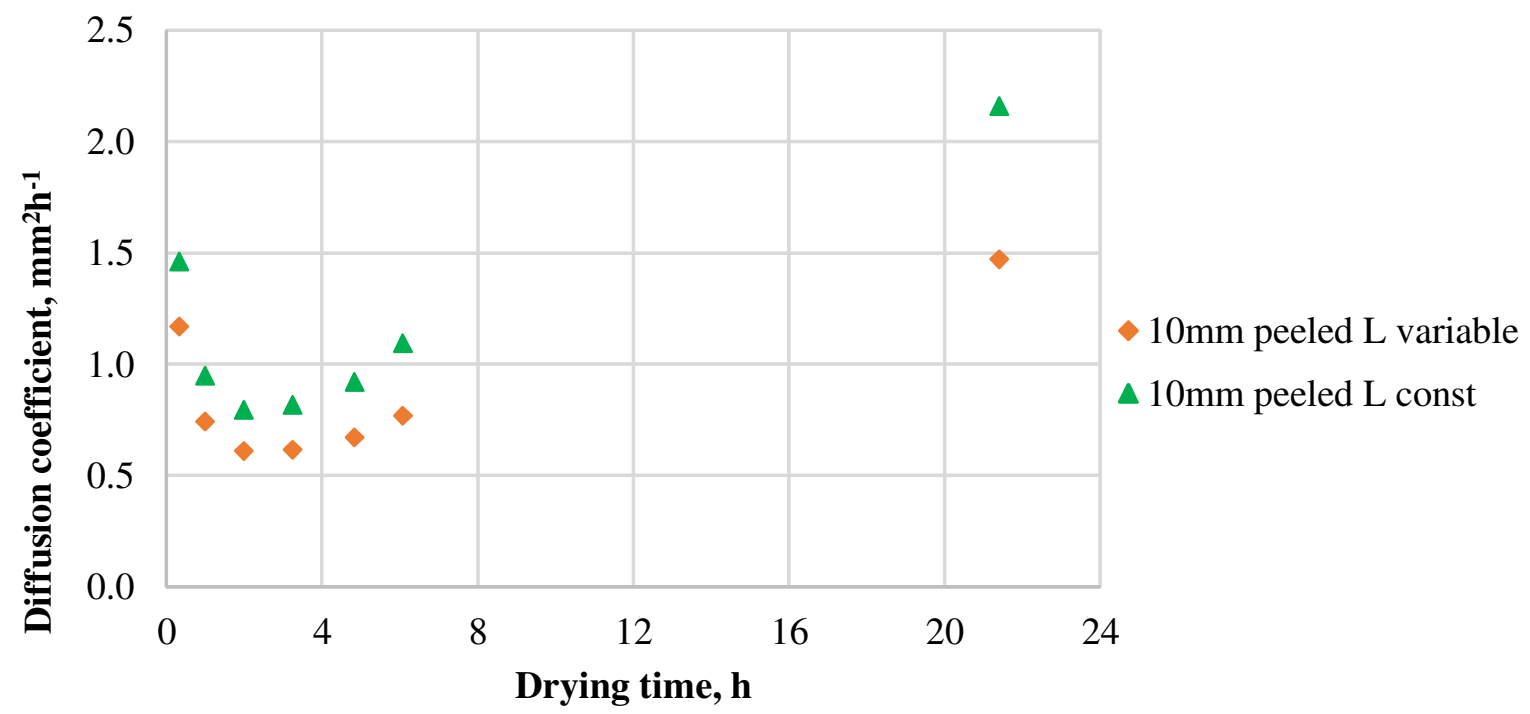

Fig. 7. Diffusion coefficient dynamics of rhubarb cubes with $10 \mathbf{~ m m}$ thickness 
The experiments carried out have shown that during the drying process not only shrinkage changes, but the whole shape of the rhubarb cube changes. For this reason the shrinkage parameters in three dimensions (width, height and thickness) were measured. Table 1 summarizes the statistical characteristics of the rhubarb cube shape for peeled and unpeeled $10 \mathrm{~mm}$ thick samples: average thickness, average width, average height, average volume and their standard deviation. The obtained results indicate that the average height and average width change much more than thickness. The phenomenon is observed at different thicknesses.

Statistical characteristics of $\mathbf{1 0} \mathbf{~ m m}$ rhubarb cubes

\begin{tabular}{|c|c|c|c|c|c|}
\hline $10 \mathrm{~mm}$ & Drying time, $\min$ & 0 & 120 & 290 & 1285 \\
\hline \multirow{5}{*}{ 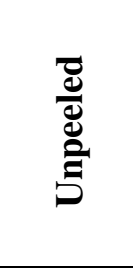 } & Average thickness, $\mathrm{mm}$ & $8.9 \pm 0.2$ & $8.8 \pm 0.2$ & $8.5 \pm 0.2$ & $8.1 \pm 0.4$ \\
\hline & Average width, mm & $16.5 \pm 0.5$ & $16.0 \pm 0.4$ & $14.4 \pm 0.5$ & $3.5 \pm 0.4$ \\
\hline & Average height, $\mathrm{mm}$ & $24.4 \pm 0.4$ & $23.8 \pm 0.4$ & $22.0 \pm 0.7$ & $8.1 \pm 0.8$ \\
\hline & Volume $\mathrm{V}, \mathrm{cm}^{3}$ & $3.60 \pm 0.13$ & $3.34 \pm 0.16$ & $2.69 \pm 0.17$ & $0.23 \pm 0.04$ \\
\hline & $\begin{array}{c}\text { Volume base growth rate, } \\
\operatorname{Tm}(\mathrm{b}), \%\end{array}$ & 100 & 92.92 & 74.63 & 6.35 \\
\hline \multirow{5}{*}{ 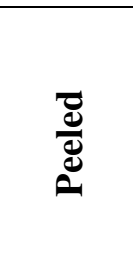 } & Average thickness, mm & $9.0 \pm 0.2$ & $8.6 \pm 0.3$ & $8.4 \pm 0.3$ & $8.1 \pm 0.4$ \\
\hline & Average width, mm & $16.6 \pm 0.8$ & $15.5 \pm 0.9$ & $14.0 \pm 1.2$ & $3.4 \pm 0.3$ \\
\hline & Average height, $\mathrm{mm}$ & $28.1 \pm 1.0$ & $26.7 \pm 1.2$ & $24.1 \pm 1.3$ & $8.3 \pm 0.7$ \\
\hline & Volume $\mathrm{V}, \mathrm{cm}^{3}$ & $4.17 \pm 0.34$ & $3.57 \pm 0.33$ & $2.84 \pm 0.4$ & $0.23 \pm 0.02$ \\
\hline & $\begin{array}{c}\text { Volume base growth rate, } \\
\operatorname{Tm}(\mathrm{b}), \%\end{array}$ & 100 & 85.67 & 68.27 & 5.4 \\
\hline
\end{tabular}

During the drying process not only shrinkage changes in fibre direction takes place, but also significant changes in side direction. It means that the surface area influences the diffusion process. In order to take into account the impact of surface area on the moisture concentration during the drying process the surface area ratio coefficient was introduced. This parameter describes ratio between the sum of the basic surface area and the area of the side surface (4).

Using the experimental data and mathematical packages MathCad and Matlab capabilities, nonlinear multivariable expression (5) was obtained between the moisture concentration $C(t, \lambda)$, drying time $t(h)$ and rhubarb samples surface area ratio $\lambda$ at the drying temperature $41 \mathrm{C}^{\circ}$ :

$$
C(t, \lambda)=0.604-7.817 \cdot 10^{-4} t+2.971 \cdot 10^{-7} t^{2}+0.42 \cdot \lambda-0.117 \cdot \lambda^{2}-4.225 \cdot 10^{-4} t \cdot \lambda
$$

with determination coefficient $R^{2}=0.982$.

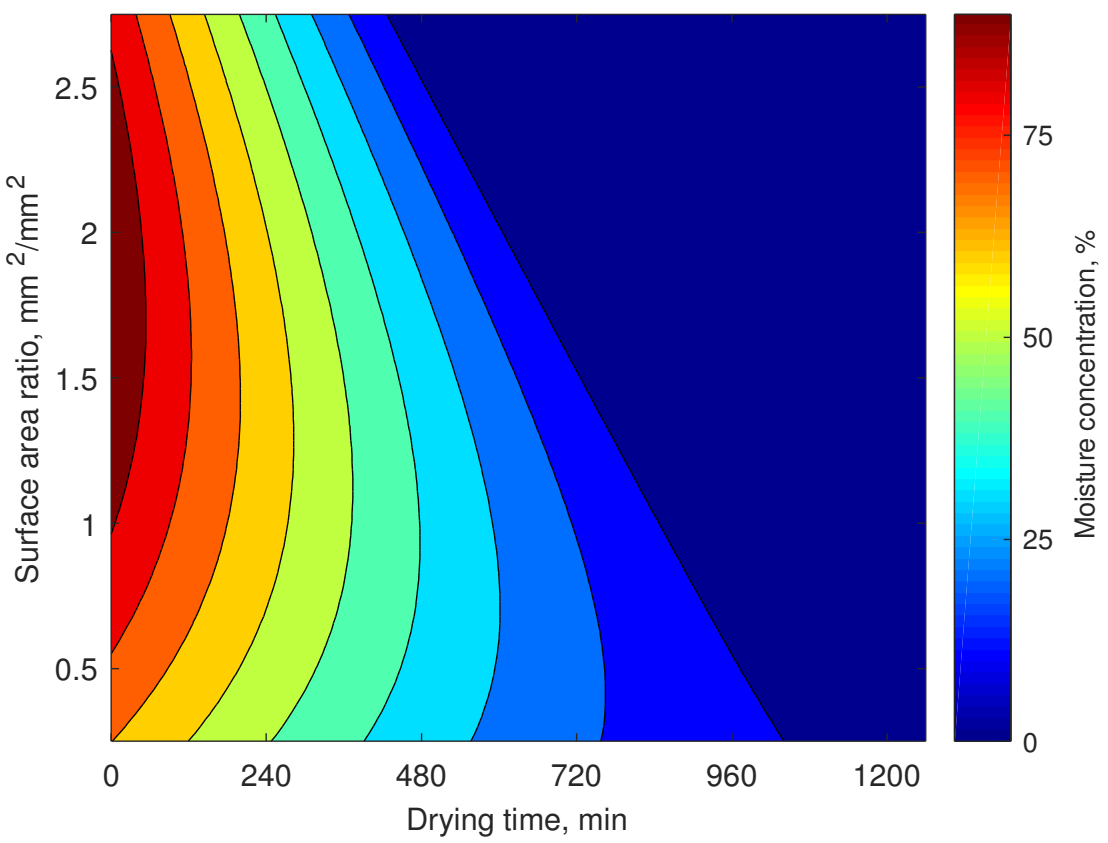

Fig. 8. Moisture concentration dependence on drying time and surface area ratio 
Graphically this relationship is presented in Fig. 8. It can be concluded that removal of moisture occurs most rapid, if the thickness of the sample is smaller.

\section{Conclusions}

1. Water removal in rhubarb pieces with thickness up to $10 \mathrm{~mm}$ emerges after 4 drying hours, but in larger samples it emerges at the beginning of the drying experiment. Regardless the thickness, water removal equalizes to the end of the drying experiment of equal length.

2. The results of the performed study have shown that during the drying process not only shrinkage changes, but the whole shape of the rhubarb cube changes. Drying experiments at different thicknesses have shown that the average height and average width changes vary considerably and much more than the thickness.

3. In order to take into account the impact of the surface area on the moisture concentration during the drying process, the nonlinear multivariable relationship between the moisture concentration $C(t, \lambda)$, drying time $t(h)$ and the rhubarb samples surface area ratio $\lambda$ was determined. The obtained relationship allows to conclude that removal of moisture occurs most rapid, if the thickness of the samples is smaller.

\section{References}

[1] Will F., Dietrich H. Processing and chemical composition of rhubarb (Rheum rhabarbarum) juice. LWT - Food Science and Technology, vol. 50(2), 2013, pp. 673-678.

[2] Encyclopaedia of Food Sciences and Nutrition (Second Edition, 2003). Available at: https://www.sciencedirect.com/topics/pharmacology-toxicology-and-pharmaceuticalscience/rhubarb

[3] Charles W.M., Carey T. Ksu horticulture report. Rhubarb. Vegetable gardens, 2001, 2 pp. Available at: https://www.bookstore.ksre.ksu.edu/pubs/EP99.pdf

[4] United States Department of Agriculture (USDA). National Nutrient Database for Standard Reference Legacy Release. Available at: https://ndb.nal.usda.gov/ndb/foods/show/09307

[5] Öztürk M., Aydoğmuş-Öztürk F., Duru M.E., Topçu G. Antioxidant activity of stem and root extracts of Rhubarb (Rheum ribes): An edible medicinal plant. Food Chemistry, Vol. 103(2), 2007, pp. 623-630.

[6] Shokravi A., Nasiri K.A. Synthesis of 1,2,3,4,5,6,7,8- Octahydro-9-ethoxy-10-hydroxy-1anthracenone (OEHA). Iranian Journal of Chemistry and Chemical Engineering, Vol.16, 1997, pp. 10-15.

[7] Bonjar H.S. Evaluation of antibacterial properties of Iranian medicinal-plants against Micrococcus luteus, Serratia marcescens, Klebsiella pneumoniae and Bordetella bronchoseptica. Asian journal of Plant Science, Vol.3, 2004, pp. 82-86.

[8] Bazzas B.S.F., Khajehkaramadin M., Shokooheizadeh H.R. In vitro antimicrobial activity of Rheum ribes extract obtained from various plant parts against clinical isolates of gram-negative pathogens. Iranian Journal of Pharmaceutical Research, Vol.2, 2005, pp. 87-91.

[9] Hudson J.B., Lee M.K., Sener B., Erdemoglu N. Antiviral activities in extracts of Turkish medicinal plants. Pharmaceutical Biology (Formerly International Journal of Pharmacognosy), Vol.38, 2000, pp. 171-175.

[10] Matsuda H., Morikawa T., Toguchida I., Park J.Y., Harima S., Yoshikawa M. Antioxidant constituents from Rhubarb: Structural requirements of stilbenes for the activity and structures of two new anthraquinone glucosides. Bioorganic and Medicinal Chemistry, Vol.9, 2001, pp. 41-50.

[11]Liu T., Zhou J., Cui H. etc. iTRAQ-based quantitative proteomics reveals the neuroprotection of rhubarb in experimental intracerebral hemorrhage. Journal of Ethnopharmacology, Vol. 232, 2019, pp. 244-254.

[12] Antal T. Comparative study of three drying methods: freeze, hot airassisted freeze and infraredassisted freeze modes. Agronomy Research, Vol.13(4), 2015, pp. 863-878. Available at: http://agronomy.emu.ee/wp-content/uploads/2015/05/13_4_1_B5.pdf

[13]Xu Y.Y., Zhang M., Tu D.Y., Sun J.C., Zhou L.Q., Mujumdar A.S. A two-stage convective air and vacuum freeze-drying technique for bamboo shoots. Int. J. Food Sci.40, 2005, pp. 589-595. 
[14] Wang H., Zhang M. Adhikari B. Drying of shiitake mushroom by combining freeze-drying and mid-infrared radiation. Food Biop. Proc. 94, 2014, pp. 507-517.

[15] Vishwanathan K.H., Giwari G.K., Herbar H.U. Infrared assisted dry-blanching and hybrid drying of carrot. Food Biop. Proc. 91, 2013, pp. 89-94.

[16] Ginzburg, A. S. Application of infrared radiation in food processing. Chemical process engineering series. London: Leonard Hill, 1969, pp. 250-255.

[17] Nowak D., Lewicki P.P. Infrared drying of apple slices. Innov. Food Sci. Emer. Technol. 5, 2004, pp. 353-360.

[18] Aboltins A., Palabinskis J., Vartukapteinis K. Studies of berry drying process in infrared film dryer. Proceeding of the International Scientific Conference Engineering for Rural Development, Latvia University of Agriculture, Jelgava, Latvia, 2017, pp. 1515-1520.

[19] Aboltins A., Palabinskis J. Fruit drying process investigation in infrared film dryer. Agronomy research, Vol. 14(1), 2016, pp.5-13.

[20] Aboltins A., Upitis A. Mathematical model of carrot drying. Proceeding of the International Scientific Conference Engineering for Rural Development, Latvia University of Agriculture, Jelgava, Latvia, 2011, pp. 88-92.

[21] Hassini L., S. Azzouz S., Belghith A. Estimation of the moisture diffusion coefficient of potato during hot-air drying. Proceedings of the $14^{\text {th }}$ International Drying Symposium (IDS 2004), São Paulo, Brazil, Vol. B, 22-25 August, 2004, pp. 1488-1495.

[22] Aboltins A., Rubina T., Palabinskis J. Shrinkage effect on diffusion coefficient during carrot drying. Agronomy research, Vol. 16(Special issue 2), 2018, pp. 1301-1311. 